\title{
The dependence of the reproductive qualities of beef-cows on the Body Condition Scoring
}

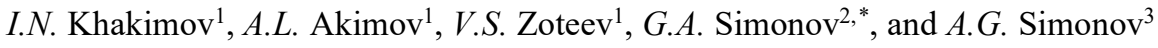 \\ ${ }^{1}$ Samara State Agrarian University, Samara, Russia \\ ${ }^{2}$ Vologda Research Center of the Russian Academy of Sciences, SZNIIMLPH, Vologda, Russia \\ ${ }^{3}$ National Research University "Higher School of Economics", Moscow, Russia
}

\begin{abstract}
A comparative assessment of the reproductive qualities of beefcows of the Hereford and Kazakh white-headed breeds is given, depending on the Body Condition Scoring. In the scientific and economic experiment in three farms on 3 groups of cows of two breeds, the influence of Body Condition Scoring on the reproductive qualities of cows was studied. It was found that cows with a Body Condition Scoring of 6 points have a significantly shorter service period (by 10-13 days) and the interval between calving (by 6-9 days), with an increase in the duration of pregnancy by 2-4 days, compared with cows with a score of 3 points. The calf crop per 100 cows, in groups with 6 Body Condition Scoring points, was higher than in groups with 3 Body Condition Scoring points by 9.2, 8.3 and $5.1 \%$.
\end{abstract}

\section{Introduction}

One of the main tasks facing the country's beef cattle breeding is to increase beef production and reduce its cost price. This task can be solved by increasing the number of livestock, the productivity of livestock, or by both. To increase the number of livestock, it is necessary to solve the problems of reproductive qualities of beef-cows. The main task of herd reproduction is to get at least one calf from each cow per year. Currently, the calf crop per 100 cows does not exceed $82 \%$.

Studies conducted by scientists from different countries earlier show that the state of Body Condition Scoring of cows affects the live weight, the level of productivity and reproductive qualities, the state of health and the duration of animal use [1-6].

The Body Condition Score (BCS) is a reliable and cheap tool for assessing the state of cow feeding and maintenance level, since regular assessment of animal Body Condition Scoring helps to identify problems in the organization of the maintenance and health of the livestock.

In this regard, the use of a beef cattle Body Condition Scoring and the study of the relationship of the Body Condition Scoring of cows of meat productivity direction with the reproductive qualities of cows is an urgent task and has great practical significance for meat farms.

\footnotetext{
*Corresponding author: gennadiy0007@mail.ru
} 
The purpose of the study is to identify the relationship between the Body Condition Scoring of cows and their reproductive qualities, and the live weight of calves when weaning from mothers.

\section{Materials and methods}

For the research, cows under the age of 5 years were used, evaluated by their appearance, constitution and body structure. Studies of the breeding stock of cows were conducted in three farms engaged in beef cattle breeding. Three groups of cows of two breeds were formed - Hereford and Kazakh white-headed. The first group included 156 Hereford cows from farm No. 1, the second group - 219 cows of the same breed from farm No. 2 and the third group - 186 Kazakh white-headed cows from farm No. 3. Within each group, the cows, depending on the state of Body Condition Scoring, were divided into 2 subgroups with Body Condition Scoring of 3 and 6 points.

Feeding and maintenance of animals was carried out using the technology of beef cattle breeding. Within their farms, the animals were kept in the same herd during the summer season in a summer camp with grazing on natural pastures, without fertilizing with concentrates. The main food for them was the green grass of steppe pastures.

During the stall-feeding period, the animals were kept in one cowshed, loosely on a deep, permanent litter. The main feed was: hay of perennial grasses, wheat straw, corn silage and grain turf in the amount of $1.5 \mathrm{~kg}$ per 1 head. The calves were kept with their mothers on suckling. In addition to the mother's milk, the calves received hay, whole grain oats, crushed grain barley and peas, salt and chalk as mineral top dressing. Weaning of young animals from mothers was performed at the age of 210 days. The weight of the calves was determined by individual weighing on an electronic scale with an accuracy of 1 $\mathrm{kg}$.

It should be noted that animal diet in the stall-feeding period of the experiment were normalized and balanced according to the existing norms of the RAAS. The positive impact of detailed animal feeding norms is reported in a number of works, for example, on productivity [7-14], growth and development [15-18], the quality of the products obtained [19], reproductive ability [20-22], which must be considered when feeding beef cattle and especially breeding stock.

The determination of the Body Condition Scoring of cows was carried out according to the recommendations set out in the practical guide on a 9-point scale 30 days before the start of the breeding season [23].

The digital material obtained during the experiment was processed by the method of biometric statistics with the determination of the difference reliability according to the Student's table.

\section{Research results}

It is well known that low Body Condition Scoring delays the onset of ovulation and increases the risk of cow culling due to dryness. Too high Body Condition Scoring of animals leads to a number of problems and diseases that characterize metabolic disorders, which ultimately affects the reproductive system of the cow. A number of problems correlate with the assessment of the condition of cows, which have a direct impact on the most important economic indicators of beef production. In emaciated animals, there is a lack of estrual cycle or incomplete estrual cycles, which makes it difficult to identify the timing of estrus, leads to a decrease in uterus fertilization after the first insemination. This leads to an extension of the service period and estrus, as a result, to an increase in the 
duration of the calving interval. A poor state of Body Condition Scoring reduces the resistance of the body and increases the susceptibility to various diseases. In addition, cows with a low state of Body Condition Scoring have a decrease in milk production, which in turn leads to a decrease in the growth energy and viability of calves.

Cows with a Body Condition Scoring of 8-9 points also have a decrease in reproductive functions, a decrease in motor activity, which leads to an increase in cases of severe calving.

In farms during the year, on average, the Body Condition Scoring of most cows was within 3-6 points. In this regard, we formed 2 groups of cows in each farm with a Body Condition Scoring of 3 and 6 points (Table 1).

Table 1. The dependence of the reproductive function of cows on Body Condition Scoring.

\begin{tabular}{|c|c|c|c|c|c|c|}
\hline \multirow{3}{*}{$\begin{array}{l}\text { Indicator } \\
\text { Body Condition } \\
\text { Scoring }\end{array}$} & \multicolumn{6}{|c|}{ Group } \\
\hline & \multicolumn{2}{|c|}{1} & \multicolumn{2}{|c|}{2} & \multicolumn{2}{|c|}{3} \\
\hline & 3 & 6 & 3 & 6 & 3 & 6 \\
\hline Number of cows & 18 & 52 & 20 & 60 & 23 & 55 \\
\hline $\begin{array}{l}\text { Duration of service } \\
\text { period, days }\end{array}$ & $82 \pm 3.51$ & $69 \pm 4.43$ & $84 \pm 3.57$ & $73 \pm 3.62$ & $86 \pm 3.17$ & $76 \pm 3.08$ \\
\hline $\begin{array}{l}\text { Duration of } \\
\text { pregnancy, days }\end{array}$ & $272 \pm 1.02$ & $276 \pm 0.87$ & $273 \pm 1.11$ & $275 \pm 1.01$ & $272 \pm 1.17$ & $276 \pm 0.89$ \\
\hline $\begin{array}{l}\text { Duration of calving } \\
\text { interval, days }\end{array}$ & $354 \pm 1.89$ & $345 \pm 1.92$ & $357 \pm 2.02$ & $349 \pm 1.86$ & $358 \pm 0.94$ & $352 \pm 1.03$ \\
\hline $\begin{array}{l}\text { Progeny received, } \\
\text { heads }\end{array}$ & 16 & 51 & 17 & 56 & 21 & 53 \\
\hline $\begin{array}{l}\text { Calf crop per } 100 \\
\text { cows, } \%\end{array}$ & 88.9 & 98.1 & 85.0 & 93.3 & 91.3 & 96.4 \\
\hline $\begin{array}{l}\text { Weight of calves at } \\
\text { weaning, } \mathrm{kg}\end{array}$ & $190 \pm 3.16$ & $211 \pm 3.53$ & $187 \pm 2.11$ & $207 \pm 3.94$ & $185 \pm 3.23$ & $206 \pm 3.76$ \\
\hline
\end{tabular}

The analysis of the reproductive function of cows shows that with a Body Condition Scoring of 3 points, 16 calves were received from 18 cows to weaning in group 1, which is $88.9 \%$ in terms of 100 cows, in group 2 - 17 calves from 20 cows, in group 3 - 21 calves from 23 cows. From cows with a Body Condition Scoring of 6 points, 51 calves were received in group I, 56 and 53 calves, which is $98.1,93.3$ and $96.4 \%$. According to the calf crop for weaning, cows with a Body Condition Scoring of 6 points outperform cows with a Body Condition Scoring of 3 points by $9.2,8.3$ and 5.1\%, respectively by groups. Kazakh white-headed cows showed better results in the calf crop per 100 cows, compared with Hereford cows with a Body Condition Scoring of 3 points - by 2.4 and $6.3 \%$.

The live weight of calves at weaning received from cows of group 1 with a Body Condition Scoring of 3 points was $190 \mathrm{~kg}$; which is $21 \mathrm{~kg}$ less than that of calves received from cows with 6 Body Condition Scoring points $(11.0 \%, \mathrm{P}>0.999)$, in the second group the difference in weight of calves was $20 \mathrm{~kg}(10.7 \%, \mathrm{P}>>0.999)$, in the third $-21 \mathrm{~kg}$ $(11.3 \%, \mathrm{P}>>0.999)$.

Cows with a Body Condition Scoring of 3 points had a longer service period, exceeding the duration of the service period of cows with a Body Condition Scoring of 6 points: in the first group by 13, in the second by 11 and in the third by 10 days. In all cases of comparison of cows with different Body Condition Scoring, the differences between the groups were significant $(\mathrm{P}>0.95)$.

An interesting fact was established when comparing cows with different Body Condition Scoring in terms of pregnancy duration. It is established that the higher the Body Condition Scoring, the longer the period of pregnancy in cows. The pregnancy period of 
cows with $\mathrm{BCS}=6$ points is greater by 4,2 and 4 days, respectively, in groups, compared with the duration of pregnancy of cows with 3 points of Body Condition Scoring.

At the same time, the duration between calving, due to a shorter service period, in cows with higher Body Condition Scoring conditions, is less by 9, 8 and 6 days, respectively, $(\mathrm{P}>0.999)$.

Our results are consistent with the results of other researchers. For example, a positive correlation between the duration of the calving interval and the Body Condition Scoring was established by R. Zotto, P. Carnier in their studies on cows of the Schwyz breed. When studying the interrelation between the assessment of Body Condition Scoring (BCS), with the interval between calving (CI), they found that the genetic correlation between $\mathrm{CI}$ and BCS was 0.44 [24].

To assess the effect of body Body Condition Scoring on the reproductive qualities of cows, K. Osoro, A. Right used data on 321 cows and found that the state of Body Condition Scoring of cows at the calving and breed were the most significant factors affecting the reproductive function of animals. Cows with a higher body Body Condition Scoring condition at the calving had shorter intervals between calving (by 11.2 days). They also found that cows of Belgian blue breed were fertilized better $(90 \%)$, and the interval between calving was shorter (364 days) than in the crossbreeds of the Frisian breed with the Hereford breed (83\%; 374 days) [25].

Lake S.L., Atkinson R.L., et al. found that the fertilization of cows at the first mating did not depend on the Body Condition Scoring at calving, but the overall pregnancy rate was higher in cows with a Body Condition Scoring of 6 points. No dependence of the live weight of calves at birth on the state of Body Condition Scoring of mothers was established. In their opinion, the general indications of the interrelation between the Body Condition Scoring and productivity indicate that cows need to reach a $\mathrm{BCS}>4$ before calving to improve their reproductive function [26].

\section{Conclusions}

Our studies have shown that the reproductive qualities of cows depend on the state of Body Condition Scoring. Cows with a Body Condition Scoring of 6 points before the breeding season have a significantly shorter service period (by 10-13 days) and the interval between calving (by 6-9 days), with an increase in the duration of pregnancy by 2-4 days, compared with cows with a score of 3 points. The calf crop per 100 cows in the groups of cows with 6 points was higher than in the groups with a Body Condition Scoring of 3 points by $9.2,8.3$ and 5.1\%. Calves received from cows with a Body Condition Scoring of 6 points, by weaning from mothers had a greater weight by $10.7-11.0 \%$ more than calves received from mothers with a Body Condition Scoring of 3 points.

\section{References}

1. I.N. Khakimov, Score of Body Condition Scoring of young beef-cattle and its correlation with live weight and productivity, Innovative achievements of science and technology of the agroindustrial complex: collection of scientific papers of the International scientific and practical conference, 18-24 (2017)

2. I.N. Khakimov, On the need for a score assessment of the Body Condition Scoring of cattle in beef-cattle breeding and its relationship with the live weight of cows, Actual issues of livestock and fish farming production: materials of the International scientific and practical Conference, 327-333 (2017) 
3. I.N. Khakimov, R.M. Mudarisov, A.L. Akimov, The score assessment of the Body Condition Scoring of beef-cattle and its application in herd management: a practical guide, 54 (Kinel: RIO SGSHA, 2016)

4. C. Bastin, S. Loker, N. Gengler, A. Sewalem, F. Miglior, J. Dairy Sci. 93 (5), 2215-2228 (2010)

5. D.E. Eversole, R.E. Dietz, Virginia Cooperative Extension 400-795, 1-24 (2007).

6. D.E. Eversole, M.F. Brown, J.B. Hall, R.E. Dietz, Body condition Scoring Beef Cows, Virginia: University of Virginia, 1-9 (2007)

7. D. Gayirbegov, Compound feed 12, 63-64 (2015)

8. V.S. Zoteev [et al.], Sheep, goats, wool business 3, 29-30 (2014)

9. A.P. Kalashnikov [et al.], Animal husbandry 9, 7-8 (1984)

10. I.V. Serebrova [et al.], Achievements of science and technology of the agroindustrial Complex 1, 48-50 (2011)

11. G.A. Simonov, A.P. Kalashnikov, M.Sh. Magomedov, Dairy and beef cattle breeding, 1, 19-21 (1985)

12. G.A. Simonov, Bulletin of the Russian Academy of Agricultural Sciences 3, 60-61 (1998)

13. E. Tyapugin [et al.], Dairy and meat cattle breeding 5, 23-24 (2011)

14. A. Ushakov, V. Epifanov, A. Mikityuk [et al.], Compound feed 12, 81-82 (2016)

15. M.M. Sadykov [et al.], Problems of the development of the agro-industrial complex of the region, 31(3(31)), 63-67 (2017)

16. G.A. Simonov, Poultry farming 6, 34-35 (2009)

17. E.A. Tyapugin [et al.], Pig breeding 1, 18-21 (2011)

18. A. Fedin [et al.], Poultry farming 9, 24 (2006)

19. G. Simonov [et al.], Dairy and beef cattle breeding 4, 19-21 (2011)

20. D. Gayirbegov [et al.], Pig breeding 1, 10-12 (2009)

21. A.P. Kalashnikov [et al.], Reports of the All-Union Academy of Agricultural Sciences named after V.I. Lenin 11, 29-30 (1984)

22. E.A. Tyapugin [et al.], Russian Agricultural Science 2, 50-54 (2018)

23. G.P. Legoshin, T.G. Sharafeeva, Point assessment of Body Condition Scoring of beef cattle and its application in herd management: a practical guide, 48 (Dubrovitsy: VIZ n.a. 1. K. Ernst, 2015)

24. R. Zotto, P. Carnier, L. Gallo, G. Bittante, M. Cassandro, Italian Journal of Animal Science 4(3), 30-32 (2005)

25. K. Osoro, I.A. Wright, J. Anim. Sci. 70(6), 1661-1666 (1992)

26. S.L. Lake, E.J. Scholljegerdes, R. L. Atkinson, J. Anim. Sci. 83(12), 2908-2917 (2005) 